\title{
Coronary artery bridging as an etiology for non- atherosclerotic myocardial infarction: A review of literature and case history
}

\author{
Jeffrey Dwyer* \\ Clinical Specialist in Cardiology, Department of Medicine, Kaiser Permanent Medical Center Vallejo, California, USA
}

\begin{abstract}
Myocardial infarction may occur without atherosclerotic lesions discernible by coronary angiography. The impact of this phenomenon may not be appreciated by many clinicians largely because of a priori assumptions that patients who present with a history of MI or angina syndrome are victims of atherosclerosis and fit well into mainstream management ranging from acute care to rehabilitation. In the absence of atherosclerosis, myocardial infarction may result from several etiologies by chronic hypoperfusion if the culprit artery has a course within the myocardium rather than a more epicardial course. These vessels, called tunnelled arteries, are typically traversed by thick bundles of muscle fibres that comprise a myocardial bridge. They are characterized by chronically abnormal hemodynamics that are prone to exacerbation, leading to anginal symptoms and myocardial infarction. A case history is presented that describes the presentation, medical evaluation and treatment, and rehabilitation of a patient with non-atherosclerotic MI attributed to a myocardial bridge. It is followed by a review of the pathophysiology of this medical problem and efficacy of various treatments. Rehabilitation considerations that apply to patients with a tunnelled coronary artery are discussed.
\end{abstract}

\section{Introduction}

Myocardial infarction may occur without atherosclerotic lesions discernible by coronary angiography [1-3]. The impact of this phenomenon may not be appreciated by many clinicians largely because of a priori assumptions that patients who present with a history of MI or angina syndrome are victims of atherosclerosis $[1,4,5]$ and fit well into mainstream management ranging from acute care to rehabilitation. Prominent textbooks [4-6], practice guidelines [7-9], and reviews [2,10-12] give little or no recognition of non-atherosclerotic causes of ischemia heart disease. Even young patients without overt risk factors for atherosclerotic vascular disease are often viewed as members of the predominant cohort [9] or a close variant of it [13]. This occurs despite the high frequency of non-atherosclerotic perfusion disorders seen in people aged 40 years or less who present, in some population centres, with symptoms of ischemia [12]. A lack of appreciation for the distinction between atherosclerotic and non-atherosclerotic ischemia heart disease may diminish the focus of services such as cardiac rehabilitation, limit the clinician's understanding of the patient's pathophysiology and risk for future cardiac events, and contribute to a tendency for inadequate evaluation [14] and medical treatment $[15,16]$.

In the absence of atherosclerosis, myocardial infarction may result from several aetiologies including vascular spasm, transient dysrhythmia, substance abuse, hypercoagulability and coronary thrombus formation, and dissection of acquired or congenital vascular anomalies $[2,3]$. The pathophysiology of these events may be exacerbated by chronic hypoperfusion if the culprit artery has a course within the myocardium rather than a more epicardial course. These vessels, called tunnelled arteries $[1,17]$ are typically traversed by thick bundles of muscle fibres that comprise a myocardial bridge [18] (Figure 1). They are characterized by chronically abnormal hemodynamics that are prone to exacerbation $[2,14,19]$ and found in up to $85 \%$ of necropsy studies performed when the suspected cause of death was heart disease $[18,20]$. Among patients who present for coronary angiography after MI or onset of angina syndrome, the incidence of a myocardial bridge is as high as $18 \%$ [17], predominantly located in the left anterior descending coronary artery $[2,17]$. The 5 -year survival is reportedly greater than $90 \%[21,22]$ but disabling symptoms, recurrent MI, serious dysrhythmia, heart failure, and sudden death are recognized as early sequelae to the discovery of a tunnelled coronary artery in a patient with chest symptoms [2,20,23-25].

This article offers a case history that describes the presentation, medical evaluation and treatment, and rehabilitation of a patient with non-atherosclerotic MI attributed to a myocardial bridge. It is followed by a review of the pathophysiology of this medical problem and efficacy of various treatments. Rehabilitation considerations that apply to patients with a tunnelled coronary artery are discussed. Several case histories are available [15,16,26-30] but none of them include information about the specific rehabilitation of these fascinating patients.

\section{Case history}

$\mathrm{KD}$ is a 45 -year-old female who experienced sudden onset, sharp, substernal chest pain while teaching at a middle school. The pain radiated to both shoulders and did not abate with rest. Prior to this event, the patient had been active without chest symptoms during

*Correspondence to: Jeffrey Dwyer, Kaiser Permanente Medical Center, 975 Sereno drive Vallejo, CA 94589, USA, Tel: 707-651-4295; E-mail: Jeff.dwyer@Kp.org

Key words: myocardial bridging, myocardial infarction, atherosclerotic, angiography

Received: April 13, 2019; Accepted: April 19, 2019; Published: April 23, 2019 


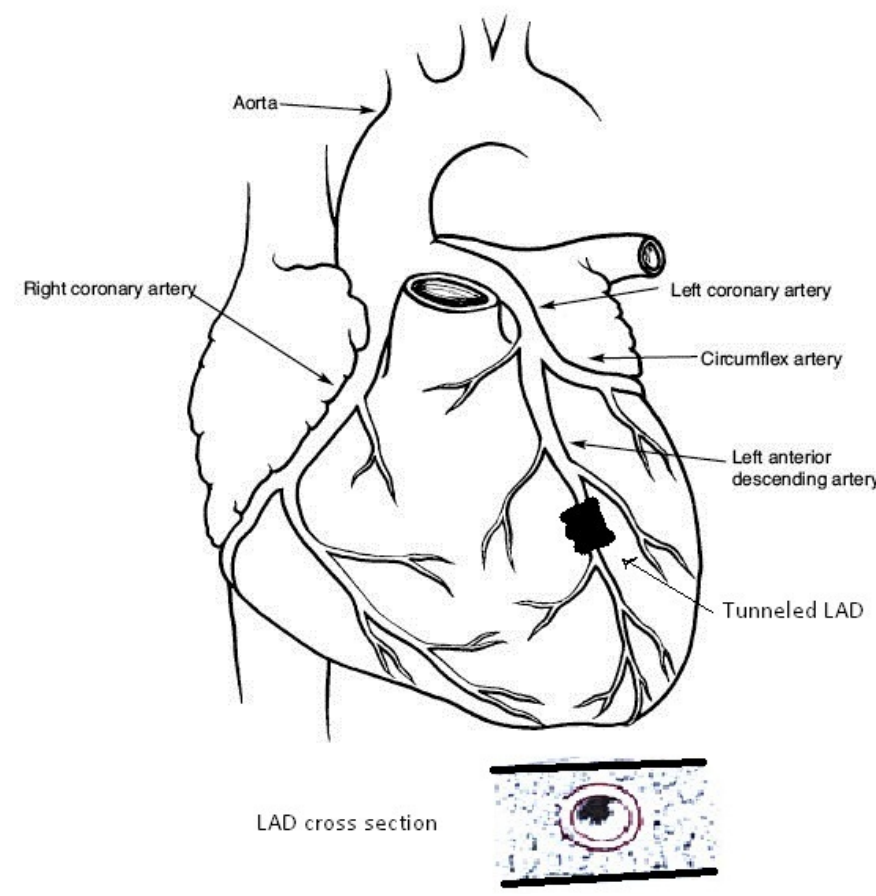

Figure 1. Diagram showing a tunneled, or "bridged" left anterior descending coronary artery (LAD). Inset: Cross section of left ventricular wall showing tunneled artery surrounded by myocardium

strength training, jogging, running, and skiing. KD drove herself to a medical clinic where she was not seen by a physician for 45 minutes due to her failure to conform to the usual stereotype for a patient with ischemic heart disease. An ECG revealed inverted T waves, inferolaterally, with abnormal $\mathrm{R}$ wave progression. She was admitted and ruled in for a non-ST elevation MI.

Aspirin, metoprolol $50 \mathrm{mg}$ BID, and lisinopril $10 \mathrm{mg}$ QD were started but intermittent chest pain persisted. At one time the pain was rated $6 / 10$ and associated with systolic BP of $80 \mathrm{~mm} \mathrm{Hg}$ and bradycardia. The beta-blocker and ACA inhibitor were held and isosorbide dinitrate $10 \mathrm{mg}$ BID was started. An echocardiogram performed one day post-MI revealed a large area of antero-apical hypokinesis with ejection fraction of $50 \%$. No mural clot was found but the patient was considered at risk for this post-MI event. Coumadin was started, and aspirin discontinued.

Risk factor assessment revealed that the patient had smoked 0.5 packs-per-day for ten years but quit 17 years prior to her MI. None of the traditional CAD risk factors were present. This very active woman had an HDL-CHOL of $81 \mathrm{mg} / \mathrm{dl}$, TOT- CHOL of $207 \mathrm{mg} / \mathrm{dl}$, and BMI of 22.5 .

Post-MI day 1, an angiogram revealed an ejection fraction of $50 \%$ with severe hypokinesis of the apical anterior wall and distal third of the inferior wall with aneurysm dilatation of the apex. The left main coronary artery (LM), left circumflex (LCX), and right coronary (RCA) arteries were angiographically normal. The anterior descending coronary artery (LAD) demonstrated a long segment bridged by myocardium. This segment rounded the apex of the heart and demonstrated complete obliteration of the vessel during systole. No intervention was performed.

Fourteen days post-NSTEMI, the patient was evaluated in the cardiac rehabilitation centre. She reported frequent episodes of chest pain characterized as "pinching" sensations with light activity despite strict compliance with medical therapy. Her exercise prescription included a target HR of $84-96 \mathrm{bpm}$ (14-16 beats/10 second count), equivalent to $20 \%$ of the HR reserve. This target HR regulated exercise at 3.5 METs, a pace that maintained the patient below her symptom threshold. KD continued cardiac rehabilitation twice each week for 8 weeks. During that time, the severity of her chest symptoms declined while the symptom-threshold increased to 7 METs with a HR of 118 bpm ( $46 \%$ HR reserve).

Eight weeks post-MI, the patient was advised that she must remain on coumadin indefinitely and that no additional medication, intervention, or follow-up echocardiogram was warranted despite limiting chest symptoms that occurred in bursts of activity, such as climbing stairs, which failed to diminish with 1 to 2 nitro-glycerine tablets. A second medical opinion was obtained, and a follow-up echocardiogram was obtained. Anterior and inferior wall segments were now mildly hypokinetic with nearly complete resolution of the aneurysm dilatation of the apex. No thrombus was seen. Coumadin was discontinued.

\section{Discussion}

Myocardial bridges are congenital [18,33,34] yet symptoms of ischemia are rare in patients younger than 35 years $[17,19,35]$. Investigations employing intravascular ultrasound and other modalities have explored this dichotomy and described the mechanisms of ischemia and factors that may lead to serious cardiac events. Features of a tunnelled artery that may be viewed as risk factors for symptomatic ischemia or myocardial infarction include age of the patient, length of the muscle bridge overlying the artery, degree of systolic compression of the vessel, number of segments or arteries tunnelled, high heart rate, degree of general myocardial hypertrophy, and depth of the tunnelled vessel [2]. Recent clinical investigations have identified successful therapeutic options and the risk of secondary events [35].

\section{Angiography}

Among patients who undergo coronary angiography after MI or ischemia, the incidence of a single myocardial bridge ranges from 1 to $18 \%$ [36-39]. This is in sharp contrast to several reports of an incidence of $58-86 \%$ detected on autopsy in persons suspected of dying from a cardiovascular disorder $[17,18,35,40,41]$. This discrepancy may result from variations in muscle fibre orientation of the myocardial bridge, bridge length, and thickness [18], degree of luminal area reduction during systole and early diastole $[15,18,42,43]$, and geometry of the segment during maximal compression [14,17]. Several investigators suggest that angiographic technique, including analytical and observational skills of the operator, contributes to success in identifying hemodynamically significant myocardial bridges $[15,17,44]$. Standard angiography may result in poorly visualized tunnelled arteries or incorrect measures of their characteristics and propensity for ischemia. When provocative drugs such as nitro-glycerine $[38,45]$, glyceryl dinitrate [46], dobutamine [44,47], and epinephrine [17] are administrated, myocardia bridges are more readily detected.

Using quantitative angiography, several studies involving a total of 80 patients indicates systolic reduction of the diameter of the bridged LAD artery by $71-83 \%[17,42-44]$. Some patients demonstrated greater than $90 \%$ luminal diameter reduction with atrial pacing at $134 \mathrm{bpm}$ [19]. In early diastole, the luminal diameter remained reduced by $34-$ $41 \%$ [19,42-44]. Noting the limitations of angiography, Ge et al. [14] used intravascular ultrasound (IVUS) to assess changes in luminal area throughout the cardiac cycle. In the normal vessel, proximal to 
the myocardial bridge, luminal area varies $9.0 \pm 7 \%$ from diastole to systole. The greatest gain occurred in mid-systole coincidental with peak pressure in the aortic root. In contrast, tunnelled arteries have a variation of $40 \pm 7 \%$, reaching the minimal lumen area in systole. The loss of luminal area persists in early diastole and becomes more pronounced in tachycardia $[19,43]$.

Several investigators $[14,15,44]$ suggest that a thorough evaluation of a tunnelled artery should include IVUS in addition to angiography. Using IVUS, Ge et al. [14] discovered atherosclerotic plaques in the LAD artery proximal to the myocardial bridge in 12-14 patients. Angiography failed to identify plaques in 8 of these patients. Using standard angiographic techniques and IVUS, Schwartz et al. [19,42] and Klues et al. [43] found no atherosclerotic lesions within bridged segments or normal segments distal to the bridge.

\section{Hemodynamics}

The phasic loss of luminal dimensions in tunnelled arteries described above results in abnormal hemodynamics in both systole and diastole. At peak systole, intra-coronary measurements of maximal pressure reveal a difference of $58.6 \pm 43 \mathrm{~mm} \mathrm{Hg}$ between the point of greatest compression on the tunnelled artery and a reference site in the proximal normal vessel coincidental with a sharp decrease in vessel area [43]. This event creates retrograde flow that early investigators labelled the milking effect [18-20]. At the onset of diastole, flow becomes antegrade with a sharp increase in flow rate due to the coincidence of maximal coronary perfusion pressure at a time when the tunnelled artery is still compressed by the myocardial bridge [14]. As vessel area increases, flow rate sharply decelerates to a plateau that persists as the myocardial bridge relaxes slowly in the remainder of diastole $[19,43]$. In contrast, IVUS and Doppler studies focused on the proximal, normal artery indicate that vessel area increases slightly throughout systole as aortic pressure rises $[19,42,43,45]$. In early diastole, flow accelerates but not sharply as seen in bridged vessels. Throughout mid- and latediastole, flow declines gradually without displaying a plateau typical of bridged vessels [14].

Coronary flow reserve (CFR), defined as the ratio of mean flow velocity at peak hyperaemia to mean resting flow velocity [35] has been used by several investigators as a sensitive index of the impact of myocardial bridging on coronary hemodynamics $[14,19,43]$ and efficacy of treatment $[19,44,46]$. Bourassa et al. [35] summarized the CFR and other hemodynamic data reported in five prominent studies. In each study, CFR distal to the bridged artery was significantly impaired, ranging from 2.0 to $2.6[14,19,42-44]$. A normal CFR exceeds 3.0. There is consensus that impaired CFR, attributed primarily to delayed early and mid-diastolic relaxation following severe systolic compression of the vessel, may collectively reduce the threshold for ischemia of the myocardium served by a tunnelled artery and explain the occurrence of angina symptoms. Confirmation is provided by Schwartz et al. [19] who measured Doppler flow velocities within tunnelled arteries during atrial pacing at $134 \mathrm{bpm}$. Tachycardia reduced the diastolic period and exacerbated abnormal hemodynamics, eliciting dyspnoea and chest pain. Intra-coronary beta-blocker medication returned all Doppler flow velocities to baseline and resolved nearly all symptoms with ECG changes despite continued pacing. Comparable results were obtained with endovascular stent placement within a bridged artery in patients with severe angina refractory to oral antianginal medical therapy $[43,44,46]$. Stent placement immediately resolved phasic loss of luminal diameter, systolic and diastolic flow abnormalities, and restored CFR to normal.

\section{Ischemia and infarction}

Early studies that considered the association between ischemia and compression of a coronary artery by myocardial bridge suggested that these vascular abnormalities are generally innocuous $[36,37,48]$ due to inconsistent correlation between limited angiographic discovery of myocardial bridging and the incidence of clinical events [19]. In the context of abnormal hemodynamics describe above, it is now recognized that tunnelled arteries can be the primary cause of dysrhythmia $[48,50]$, including atrial fibrillation [51], angina [16,26$29,37]$, myocardial infarction [24,52-54], and sudden death [24,25,51].

Disparity between the anatomic incidence of bridged arteries and the incidence of clinical events is likely due to an interaction of several fixed and transient factors $[15,18,19,26,31,35]$. Tunnelled segments of coronary arteries greater than $3 \mathrm{~cm}$ in length that lie deep in the myocardium are more likely to generate abnormal hemodynamics that lead to ischemia and MI $[2,17]$ than short, shallow tunnels. Moreover, ischemia is more likely to occur when muscle fibres of the over-lying myocardium cross the artery obliquely or helically [18]. This condition may create the greatest degree of vessel distortion during systole and delay diastolic relaxation [55] compared to bridges that cross perpendicularly. Deep bridges with oblique fibres can twist an artery, exacerbating abnormal hemodynamics and creating intimal damage that increases propensity for platelet aggregation [56]. Compression of the vessel may be minimal if loose connective and adipose tissue dampens the compressive force of the bridge. If interposed tissue is sparse, vessel compression may be substantial. Aortic outflow tract obstructions may enhance vessel compression due to increased tension in the myocardium that substantially exceeds intracoronary blood pressure. Similar hemodynamics are created if stenosis of the vessel occurs proximal to the bridged segment. Reduced intracoronary pressures distal from the stenotic segment will increase the transmural pressure gradient at the site of tunnelling, favouring vessel compression.

Spasm of a tunnelled coronary artery has been cited as a predominant transient factor leading to significant clinical events [2,15,31]. Several investigators implicate heavy cigarette smoking $[15,16]$, extreme alcohol consumption, and substance abuse [58-60] as provocative agents. Many pharmacologic agents may induce spasm of tunnelled arteries [17]. Intracoronary injection of dobutamine, epinephrine, or isoproterenol severely exacerbate vessel narrowing in systole and delay of diastolic relaxation $[17,47,48]$. Similar effects were found with either intracoronary or sublingual nitro-glycerine [38]. The deleterious effect of nitro-glycerine used sublingually by symptomatic patients with bridged arteries was recognized by several investigators $[16,27,38]$.

Several authors $[14,38,61]$ suggest that abrupt, severe tachycardia may create spasm in tunnelled arteries. There are no studies, however, that offer hemodynamic or angiographic evidence of spasm in tunnelled or normal vessels as a result of spontaneous tachycardia. Schwarz et al. [19] found that atrial pacing at $134 \mathrm{bpm}$ severely exacerbated the hemodynamics in tunnelled LAD arteries in 15 patients. Similar results have been found with incremental dobutamine infusion [44].

Coagulation disorders are cited by several authors [15,22,31,57,62] as significant etiological factors in MI not associated with CAD, especially in young people. With one exception, the author found no case histories of patients with MI associated with a tunnelled arty that clearly implicated a coagulation disorder. The exception describes a case in which a hyper-coagulable state, resulting from nephrotic syndrome, was associated with $\mathrm{MI}$ in a young person without coronary atherosclerosis [63]. 


\section{Medical therapy}

It is generally accepted that negative inotropic agents lower systemic and transmural pressures and reduce the extent of compression of tunnelled arteries [23,64]. Schwarz et al. [19] described the effects of intracoronary infusion of esmolol on hemodynamics during atrial pacing at $134 \mathrm{bpm}$ in 12 patients. The beta-blocker reversed the negative effects of tachycardia on average diastolic peak flow velocity within the bridged segment without affecting flow velocity in segments proximal and distal segments. During pacing, average peak flow velocity and diastolic/systolic flow velocity ratio were restored to baseline levels by this medication. Symptoms elicited by the tachycardia were completely resolved in 8 of 9 patients while ECG changes normalized in 5 patients. In contrast to this compelling data, there are no meta-analyses or large studies that describe the long-term clinical efficacy of beta-blocker therapy in symptomatic patients with ischemia or history of MI caused by a bridged coronary artery. Two studies report successful betablocker therapy up to one-year post-MI but only three patients were followed [23,27]. Several others have not found beta-blocker to be substantially effective in controlling symptoms of ischemia in post-MI patients with a myocardial bridge [16,26,43-46,61].

If spasm is indicated as an etiological factor, several authors recommend a calcium channel blocker $[16,21,61,65]$ and an ACE inhibitor or angiotensin receptor inhibitor [21]. Tauth and Sullenberger [28] used diltiazem CD $240 \mathrm{mg}$ /day with success in a 38-year-old man but no long-term follow-up was reported. In contrast, de Winter et al. [16] described a 47-year-old man with chest pain caused by spasm of a bridged artery. He was discharged from the hospital after a negative treadmill test and treated with nifedipine $60 \mathrm{mg}$ daily. Within four weeks he was readmitted with marked ECG indications of ischemia. Similarly, Haager et al. [44] reported failure of anti-angina medical therapy in 9 of 11 patients with angina and a history of MI associated with a bridged LAD artery.

Several authors advise limited use of nitro-glycerine for symptoms of ischemia [16,17,27,38]. Angellini et al. [17] demonstrated severe exacerbation of vessel compression by sublingual or intra-coronary nitro-glycerine. This medicine may enhance contraction of the bridged myocardium, further reducing coronary flow reserve [27,38]. Bashour et al. [27] recommend sublingual nitro-glycerine only for prolonged episodes of severe chest pain associated with ST-segment elevation. The efficiency of long-acting oral nitrates has not been studied. Schwarz et al. [19] suggest that benefits may be derived from reduced pre-load and suppression of vasospasm.

\section{Invasive treatment}

With the advent of intracoronary stents, clinicians theorized that these devices would provide internal stabilization of the lumen of tunnelled arteries by counteracting transmural forces and resolving abnormal hemodynamics [46]. Haager et al. [44] stipulated that the stent must be highly flexible or modular, and span at least $90 \%$ of the length of the tunnelled segment, to provide optimum flow and prevent ischemia.

Several studies have described the clinical course that led to stent implantation in tunnelled coronary arteries $[15,16,26,44,46]$. With one exception, each of these studies included 4 patients or less. Haager et al. [44] studied 11 patients with ischemia or MI attributable to a tunnelled vessel. A total of eighteen stents were deployed in the group and the patients followed for two years. Four patients experienced anginal symptoms less than seven weeks after the procedure while a fifth patient was found to have greater than $50 \%$ in-stent stenosis without symptoms. Two patients received additional stents and remained symptom-free over the next six months. Two others required surgery with a LIMA graft to the LAD. Several case histories point to high failure rates of stents in tunnelled vessels $[14,16,46,66]$. Haager et al. [44] suggest that persistent external compression of a tunnelled segment might create shear stress that leads to intimal proliferation and in-stent stenosis. Proliferation of the endothelium due to damage incurred during balloon inflation and early mechanical recoil or shrinkage of the stent scaffolding may also contribute to early loss of luminal diameter [26].

In patients with long bridged segments, a surgical option may be preferable to stent deployment [29,44,46,67]. Tio et al. [47] found a 7 $\mathrm{cm}$ bridge of the LAD in a 46-year-old survivor of an event they called "sudden cardiac near-death." Grossly abnormal hemodynamics in this vessel indicated the surgical option. A $5 \mathrm{~mm}$ thick muscular bridge was divided without complication. Three weeks later, angiography revealed complete resolution of the bridge and normal hemodynamics. Furnnis et al. [29] also achieved resolution of a LAD bridge by myotomy in a 47-year-old man. Prior to surgery, nuclear imaging demonstrated a stress-induced anterolateral perfusion defect. After ostomy, this defect was not observed, and all symptoms were resolved.

Cleavage of muscle fibres that comprise a bridge requires deep incisions of the ventricular wall and may result in a mural aneurysm [68] or inadvertent opening of the right ventricle [47]. Prendergast et al. [46] suggests that myotomy may be no better than medical therapy because scar tissue development in the myocardium may compress the underlying vessel. Interestingly, Tio et al. [47] observed vessel spasm three weeks post-myotomy. They suggest that this event was the result of inflammation of the vessel wall and/or post-operative scar formation. Pratt et al. [69] recommend coronary artery by-pass graft surgery as an alternative to myotomy or endovascular stent placement. They describe two successful cases using the minimally invasive technique. De Winter et al. [16] and Prendergast et al. [46] argue that surgical procedures should be considered only upon failure of an endovascular stent because ischemia from a tunnelled artery is usually a single vessel disorder. Unfortunately, the patient described by Prendergast et al. [46] sustained an anterior MI when his stent failed after three years. Haager et al. [44] found that 5 of their 11 patients had in-stent stenosis and abnormal hemodynamics only seven weeks after stent deployment in the LAD. Two of these patients underwent CABG and remained free of symptoms during a two-year period of clinical monitoring.

\section{Cardiac rehabilitation}

Te cardiac rehabilitation of patient KD was challenging because of basic differences between victims of atherosclerotic ischemia heart disease and those with a myocardial bridge. In contrast to typical patients with anterior MI, KD suffered an infarction at an early age after decades of practicing an active lifestyle that included vigorous aerobic training activities. She possessed none of the traditional CAD risk factors, no intervention was attempted, and no plan was established for rigorous medical follow-up. Furthermore, KD endured an extended period post-MI during which she was limited by anginal symptoms despite medical therapy.

$\mathrm{KD}$ was frustrated by the lack of information from her doctors concerning the etiology of her cardiac illness, efficacy of treatment options, prognosis, and the abrupt change from an intensely active lifestyle to one quite limited by symptoms. Discussion of these concerns comprised a significant portion of the education component 
of cardiac rehabilitation. Without CAD risk factors, the usual core elements and goals of traditional patient education course were not relevant. Emphasis was placed on behavior modification with respect to symptom recognition and self-pacing of activities of daily living. Unfortunately, no search was conducted for occult risk factors, or factors associated with non-atherosclerotic MI identified by DaCosta et al. [31].

At 14 days post-MI, patient $\mathrm{KD}$ was highly symptomatic at low exercise intensities despite treatment with isosorbide dinitrate $20 \mathrm{mg}$ BID. There are no studies that compare the efficacy of this medicine to calcium channel blockers, or other medications, in this subgroup of MI patients. Sub-lingual nitrates administered for episodes of chest pain have been found to exacerbate the abnormal hemodynamics of tunnelled arteries $[17,27,38]$. However, nitrates may be beneficial in some patients by reducing pre-load and suppression of vasospasm [19]. During KD's hospitalization and convalescence here was no trial with a calcium channel blocker despite recent literature suggesting this class of medication can be efficacious $[28,65]$.

KD's angiogram did not identify atherosclerotic stenosis in any coronary artery. Several studies report no angiographic evidence of CAD in bridged vessels associated with symptoms or MI [15,26,28,44,46]. In fact, it has been suggested that tunnelled arteries may be protected against the development of CAD [41,70]. Consequently, it is widely held that atherosclerotic disease is not associated in any way with the phenomenon of myocardial bridging. Using IVUS, however, Ge et al. [14] discovered significant atherosclerotic plaques proximal to bridged LAD in eight patients with angiographically normal arteries. It was suggested that the normal, proximal segment may be subjected to wall stress from abnormal flow and shear downstream. Shear stress may injured the vessel wall and lead to intramural plaque formation without loss of lumen [71]. Ge et al. [14] and others [56] suggest that IVUS should be used routinely in patients identified with a myocardial bridge to more fully evaluate the vessel's status and establish the patient's risk of future events.

KD's exercise prescription included an unusually low relative HR based upon her threshold for symptoms in treadmill walking and cycling. Persistent anginal symptoms that improved slowly over several weeks were likely emanating from injured, peri-infarct tissue to which perfusion remained abnormal. At 10 weeks post-MI, KD's target heart rate was only $46 \%$ of $\mathrm{HR}$ reserve ( 7.0 METs) due to chest pain rated 2-3/10 despite the continued use of isosorbide dinitrate. At 14 weeks post-MI, KD returned to work and resumed an active but very limited lifestyle. Approximately one year later, she was admitted to the hospital with chest pain that began after a session of moderate paced exercise. Her symptoms onset while driving her car and were not relieved with NTG x 2 . The second NTG tablet worsened her symptoms. KD ruled out for an MI and performed a treadmill test without indications of ischemia. It was concluded that vessel spasm caused her symptoms but no search for precipitating factors was conducted. Medical therapy was modified to include a low-dose calcium channel blocker with continuation of isosorbide dinitrate.

\section{Summary}

Patients who present for cardiac rehabilitation after MI associated with a myocardial bridge may be highly symptomatic. Medical therapy or vascular invention may not offer the same degree of success experienced by patients who have atherosclerotic vascular stenosis as a basis of their MI. Routine evaluations of patients with a myocardial bridge-including angiography-may incompletely describe the patient's pathophysiology and risk of future cardiac events. Cardiac rehabilitation clinicians may be able to gather data that clearly defines the patient's functional status and serves as a foundation for medical decision-making processes, particularly about medications.

\section{References}

1. Waller BF (1989) Atherosclerotic and non-atherosclerotic coronary artery factors in acute myocardial infarction. Cardiovasc Clin 20: 29-104. [Crossref]

2. Waller BF (1998) Non-atherosclerotic coronary disease. In: Alexander RW, Schlan RC, Fuster V., eds. Hurst's The Heart Vol 1. Philadelphia: McGraw-H8ill 1197-1240.

3. Lew WYW, LeWinter MN (1992) Acuta myocardial infarction: Pathophysiology. In: Parmley WW, Chatterjee K, eds. Cardiology. Philadelphia: Lippincott.

4. Squires RW, Williams WL (1993) Coronary atherosclerosis and acute myocardial infarction. In: American College of Sports Medicine. Resource Manual for Guidelines for Exercise Testing and Prescription. $2^{\text {nd }}$ edition, Philadelphia: Lea and Febiger, 168-186.

5. Hillegass EA, Sadowsky HS (1994) Essentials of Cardiopulmonary Physical Therapy. Philadelphia: WB Saunders.

6. Wenger, NK, Smith LK, Froelicher ES (1999) Cardiac Rehabilitation: A Guide to Practice in the $21^{\text {st }}$ Century. New York: Marcel Dekker.

7. American College of Sports Medicine. (2001) Resource Manual for Guidelines for Exercise Testing and Prescription. 3nd edition, Philadelphia: Lea and Febiger.

8. American Association for Cardiovascular and Pulmonary Rehabilitation. (1999) Guidelines for Cardiac Rehabilitation Programs. $3^{\text {rd }}$ edition. Champaign, Ill: Human Kinetics.

9. Wenger NK, Smith LK, Froelicher ES, et al (1995) Clinical Practice Guideline No. 17: Cardiac Rehabilitation. Agency for Health Care Policy and Research ad NIH (Publication 96-0672).

10. Frownfelter DL, Dean E (1996) Principles and Practice of Cardiopulmonary Physical therapy, $3^{\text {rd }}$ edition. New York: Mosby-Yearbook.

11. Oldridge NB, Guyatt GH, Fischer ME, Rimm AA (1988) Cardiac rehabilitation after myocardial infarction: combined experience of randomized clinical trials. JAMA 260: 945-950. [Crossref]

12. O'Connor GT, Burning JE, Youeuf S, Goldhaber SZ, Olmstead EM, et al. (1989) An overview of randomized trials of rehabilitation with exercise after myocardial infarction. Circulation 80: 234-244. [Crossref]

13. Virmani R, Rupprecht RJ, Kock L (1993) Ischemia from myocardial coronary bridging: fact or fancy? Humn Pathol 24: 687-688. [Crossref]

14. Ge J, Erbel R, Rupprecht RJ, Kock L, Kearney P, et al. (1994) Comparison of intravascular ultrasound and angiography in the assessment of myocardial bridging. Circulation 89: 1725-1732. [Crossref]

15. Williams MJA, Restieaux NK, Low CJ (1998) Myocardial infarction in young people with normal coronary arteries. Heart 79: 191-194. [Crossref]

16. DeWinter RJ, Kok WEM, Piek JJ (1998) Coronary atherosclerosis within a myocardial bridge, not a benign condition. Heart 80: 91-93. [Crossref]

17. Angelini P, Trivellato M, Donis J, Leachman RD (1983) Myocardial bridges: a review. Prog Cardiovasc Dis 26: 75-88. [Crossref]

18. Ferrier AG, Trotter SE, Knig B, Decourt LV, Fox K, et al. (1991) Myocardial bridges: morphological and functional aspects. Brit Heart $J$ 66: 364-367. [Crossref]

19. Schwarz ER, Klues HG, Yom Dahl J, Klein I, Krebs W, et al. (1996) Functional, angiographic, and intracoronary Doppler flow characteristics in symptomatic patients with myocardial bridging: effect of acute intravenous beta-blocker medication. $\mathrm{J} \mathrm{Am}$ Coll Cardiol 27: 1637-1645. [Crossref]

20. Ross L, Dander B, Nidasio GP, Arbustini E, Paris B, et al (1980) Myocardial bridges and ischemia heart disease. Europ Heart $J$ 1: 239-245. [Crossref]

21. Alpert JS (2001) Fascination with myocardial infarction and normal coronary arteries. Europ Heart J 22: 1364-1366. [Crossref]

22. Raymond R, Lyunch J, Underwood D, Leatherman J, Razavi M (1988) Myocardial infarction and normal coronary arteriography: a 10-year clinical and risk analysis of 74 patients. J Am Coll Cardiol 11: 471-477. [Crossref]

23. Bestetti RB, Dinzi LA, Amaral FT, Secches AL, Oliveira JS (1987) Myocardia bridging of coronary arteries associated with an impending acute myocardial infarction. Clin Cardiol 10: 129-131. [Crossref] 
24. Bestetti RB, Costa RS, Zucolotto S, Oliveira JS (1989) Fatal outcome associated with autopsy-proven myocardial bridging of the left anterior descending coronary artery. Europ Heart J 10: 5763-576. [Crossref]

25. Bestetti RB, Costa RS, Kazava DK, Oliviera JS (1991) Can isolated myocardial bridging of the left anterior descending coronary artery be associated with sudden death during exercise? Acta Cardiol 46: 27-30. [Crossref]

26. Bayes A, Marti V, Auge JM (1998) Coronary stenting for symptomatic myocardial bridging. Heart 80: 102-103. [Crossref]

27. Bashour TT, Espinosa E, Blumenthal, Wong T, Mason DT J (1997) Myocardial infarction caused by coronary artery bridge. Am heart $J$ 133: 473-477. [Crossref]

28. Tauth J, Sullebarger JT (1997) Myocardial infarction associated with myocardia bridging: case history and review of the literature. Cathet Cardiovasc Diagn 40: 364367. [Crossref]

29. Furniss SS, Williams DO, McGregor CG (1990) Systolic coronary occlusion due to myocardial bridging-rare cause of ischemia. Int J Cardiol 226: 116-117. [Crossref]

30. Baldassarre S, Unger P, Renard M (1996) Acute myocardial infarction and myocardial bridging: a case report. Acta Cardiol 51: 461-465. [Crossref]

31. DaCosta A, Isaac K, Faure E, Mourot S, Cerisier A, et al. (2001) Clincial characteristics, aetiological factors, and long-term prognosis of myocardial infarction with an normal coronary angiogram. Europ Heart J 22: 1459-1465. [Crossref]

32. Cheitlin, MD, McAllister, HA, de Castro CM (1975) Myocardial infarction withou atherosclerosis. JAMA 231: 951-959. [Crossref]

33. Visscher, DW, Miles BL, Waller BF (1983) Tunneled ("bridged') left anterior descending coronary artery in a newborn without clinical or morphological evidence of myocardial ischemia. Cathet Cardiovasc Diagn 9: 493-496. [Crossref]

34. Von Polucek P, Kralove H (1961) Relation of myocardial bridges and loops on the coronary arteries to coronary occlusions. Am Heart J 61: 44-52. [Crossref]

35. Bourassa MG, Butnaru A, Lesperance J, Tardif JC (2003) Symptomatic myocardial bridges: overview of ischemia mechanisms and current diagnostic and treatment strategies. J Am Coll Cardiol 41: 351-359. [Crossref]

36. Kramer JR, Kitazume H, Produin WI Sones IM (1982) Clinical significance of isolated coronary bridges: Benign and frequent condition involving the left anterior descending artery. Am Heart J 103: 283-288. [Crossref]

37. Noble J, Bourassa MG, Petitclerc R, Dyrda I (1976) Myocardial bridging and milking effect of the anterior descending coronary artery: normal variant or obstruction? Am J Cardiol 37: 993-999. [Crossref]

38. Ishimori T, Raizner SF, Chabine RA, Awdeh M, Luchi RJ (1977) Myocardial bridges in man: correlations and angiographic accentuation with nitroglycerine. Cathe Cardiovasc Diagn 3: 59-65. [Crossref]

39. Channer KS, Bukis E, Hartnell G, Ress JR (1989) Myocardial bridging of the coronary arteries. Clin Radiol 40: 355-359. [Crossref]

40. Polacek P, Zechmesiter A (1968) the occurrence and asignificiance of myocardia bridges and loops on coronary arteries. Opuscola Cardiologica, Acta Facultatis Medicae Unversitatis Brunenses, Brne.

41. Lee SS, Wu TL (1972) The role of the mural coronary artery in prevention of coronary atherosclerosis. Arch Pathol 93: 32-35. [Crossref]

42. Schwarz ER, Klues HG, von Dahl J, Klein I, Krebs W, et al. (1997) Functiona characteristics of myocardial bridging: A combined angiographic and intracoronary Doppler flow study. Europ Heart J 18: 434-442. [Crossref]

43. Klues HG, Schwarz ER, von Dahl J, Reffelmann T, Reul H, et al. (1997) Disturbed intracoronary hemodynamics in myocardial bridging. Circulation 96: 2905-2913. [Crossref]

44. Haager PK, Schwarz ER, von Dahl J, Klues HG, Reffelmann T, et al. (2000) Long term angiographic and clinical follow up in patients with stent implantation for symptomatic bridging. Heart 84: 403-408. [Crossref]

45. Iversen S, Hake U, Mayer E, Erbel R, Diefenbach C, et al. (1992) Surgical treatment of myocardial bridging causing coronary artery occlusion. Scand J Cardiovasc Surg 23: 107-111. [Crossref]

46. Prendergast BD, Kerr F, Starkey IR (2000) Normalization of abnormal coronary fractional flow reserve associated with myocardial bridging using an intracoronary stent. Heart 83: 705-707. [Crossref]

47. Tio RA, Van Gelder IC, Boonstra PW, Ceijns HJ (1997) Myocardial bridging in a survivor of sudden cardiac near-death: role of intracoronary Doppler flow measurements and angiography during dobutamine stress in the clinical evaluation. Heart 77: 280-282. [Crossref]
48. Robert WC (1986) Major anomalies of coronary arterial origin seen in adulthood. $\mathrm{Am}$ Heart J 111: 941-963. [Crossref]

49. Field H, Guadanino, Hollander G, Greengart A, Lichstein E, et al. (1991) Exerciseinduced ventricular tachycardia in association with myocardial bridge. Chest 99: 12951296. [Crossref]

50. Den Dulk D, Brugada P, Braat S, Heddle B, Wellens HJ (1983) Myocardial bridging as a cause of paroxysmal atrioventricular block. J Am Coll Cardiol 1: 965-970. [Crossref]

51. Morales AR, Romanelli R, Boucek RJ (1980) The mural left anterior descending coronary artery: strenuous exercise and sudden death. Circulation 62: 230-237. [Crossref]

52. Vasan RS, Bahl VK, Rajano M (1989) Myocardial infarction associated with a myocardial bridge. Int J Cardiol 25: 240-241. [Crossref]

53. Feldman AM, Baughman B (1986) Myocardial infarction associated with a myocardial bridge. Am Heart J 111: 784-787. [Crossref]

54. Chee, TP, Jensen, DP, Padnick MB, Cornell WP, Desser KB, et al. (1981) Myocardial bridging of the left anterior descending coronary artery resulting in subendocardial infarction. Arch Intern Med 141: 1703-1704. [Crossref]

55. Hill RC, Chiwood WR, Bashour TM, Sink JD, Cox JL, et al. (1981) Coronary flow and regional function before and after supra-arterial myotomy for myocardial bridging. Ann Thorac Surg 31: 176-181. [Crossref]

56. Musialek P, Kardos P, Banning AL (1999) Myocardial infarction in young people with normal arteries. Heart 81: 451. [Crossref]

57. Altura BM, Altura BT, Carella A (1983) Ethanol produces coronary spasm: evidence for a direct action of ethanol on vascular muscle. Brit J Pharmacol 78: 260-262. [Crossref]

58. Vincent GM, Anderson JL, Marshall HW (1983) Coronary spasm producing coronary thrombus and myocardial infarction. $N$ Eng J Med 309: 220-223. [Crossref]

59. Zimmerman FH, Gustafson GM, Kemp HG (1987) Recurrent myocardial infarction associated with cocaine abuse in a young man with normal coronary arteries: evidence for coronary artery spasm culminating in thrombosis. J Am Coll Cardiol 9: 964-968. [Crossref]

60. Williams, MJA, Stewart RAH (1997) Serial angiography in cocaine-induced myocardial infarction. Chest 111: 822-824. [Crossref]

61. Elyounassi B, Kebdoussi M, Khatouri, Fall PD, Mouyopa C, et al. (1998) Muscle bridge and myocardial ischemia. Study of 6 cases. Ann Cardiol Angeiol 47: 459-463. [Crossref]

62. Fuster V, Chesebro JH, Frye RL, Elveback LR (1981) Platelet survival and the development of coronary artery disease in the young adult: effects of cigarette smoking, strong family history, and medical therapy. Circulation 63: 546-551. [Crossref]

63. Osula S, Bell GM, Hornung RS (2002) Acute myocardial infarction in young adults causes and management. Post Grad Med J 78: 27-30. [Crossref]

64. Nair CK, Dang B, Heintz MH, Sketch MH (1998) Myocardial bridges: effects of propranolol on systolic compression. Can J Cardiol 2: 218-221. [Crossref]

65. Podbielski FJ, Chaer R, Massad MG, Chami YG, Nawas S, et al. (1998) What makes a coronary bridge symptomatic? Minerva Cardioangiol 46: 127-130. [Crossref]

66. Antonellis IP, Patsilinakos SP, Pamboukas CA, Kranidis AJ, Margaris NG, et al. (1999) Intracoronary stent placement proximal to a myocardial bridge: immediate and longterm results. Catheter Cardiovasc Interv 46: 363-367 [Crossref]

67. Prasad VS, Shivaprakash K, Arumugan SB, Cherian KM (1995) Modified supraarterial myotomy for intermittent coronary obstruction by myocardial bridges. Scand $J$ Thoracic Cardiovasc Surg 29: 91-93. [Crossref]

68. De Zwaan C, Wellens HJJ (1984) Left ventricular aneurysm subsequent to cleavage of myocardial bridging of a coronary artery. J Am Coll Cardiol 3: 1345-1348. [Crossref]

69. Pratt JW, Michler RE, Pala J, Brown DA (1999) Minimally invasive coronary artery bypass grafting for myocardial bridging. Heart Surg Forum 2: 250-253. [Crossref]

70. Ishii T, Asuwa N, Masuda S Ishikawa Y (1998) The effects of a myocardial bridge on coronary atherosclerosis and ischemia. J Pathol 185: 4-9. [Crossref]

71. Ge J, Erbel R, Gorge G, Haude M, Meyer J (1995) High wall shear stress proxima to myocardial bridging and atherosclerosis: intracoronary ultrasound and pressure measurements. Brit Heart J 73: 462-465. [Crossref]

Copyright: (C2019 Dwyer J. This is an open-access article distributed under the terms of the Creative Commons Attribution License, which permits unrestricted use, distribution, and reproduction in any medium, provided the original author and source are credited. 